\title{
Growing by learning: firm-level evidence on the size-productivity nexus
}

\author{
Enrique Moral-Benito ${ }^{1}{ }_{\mathbb{D}}$
}

Received: 6 November 2017 / Accepted: 16 February 2018 / Published online: 2 March 2018

(C) The Author(s) 2018. This article is an open access publication

\begin{abstract}
A well-known empirical regularity is that small firms are less productive than large firms. However, does size cause productivity or vice versa? Using firmlevel administrative data for Spain, I find that productivity shocks are followed by significant increases in size defined by employment. In contrast, size shocks are not followed by productivity gains at the firm level. The combination of matching methods together with a bi-directional identification strategy allows me to account for selection on observables and endogeneity. I label this pattern as growing by learning because those firms learning about their higher efficiency levels are those that happen to grow more.
\end{abstract}

Keywords Firm-level data $\cdot$ Productivity $\cdot$ Size distribution

JEL Classification L11 $\cdot$ L25 · D24

\section{Introduction}

In Spain and other Southern European countries there is a large number of small firms in comparison to other developed economies. On the other hand, large firms are more productive than small ones. As a result, it is typically argued that a firm size distribution biased towards small firms hampers productivity growth in Spain. Understanding the

I thank Roberto Ramos and Eric Bartelsman for insightful suggestions. I also thank seminar participants at the Banco de España and SAEe Bilbao 2016. The opinions and analyses are the responsibility of the author and, therefore, do not necessarily coincide with those of the Banco de España or the Eurosystem.

Enrique Moral-Benito

enrique.moral@gmail.com

1 Banco de España, Madrid, Spain 
obstacles to firm growth in those countries is thus at the center of the policy debate (IMF 2015). ${ }^{1}$

However, causality between firm size and firm productivity may operate in both directions. On the one hand, there are models of firm growth that characterize industries as groups of heterogeneous-productivity firms under the assumption that they learn about their productivity as they operate in the market [see for instance (Jovanovic 1982; Melitz 2003)]. Firms maximize profits choosing the level of employment (and capital) given their productivity shocks, which are assumed to be exogenous. Low productivity firms are less likely to survive and thrive than their more efficient counterparts. On the other hand, there are also mechanisms rationalizing an effect from firm size to productivity growth: expanding firms may invest in new technologies, learn about more efficient methods of production, use more specialized inputs, and/or better coordinate their resources. Nevertheless, these mechanisms are discussed heuristically in some papers [see for instance (Thompson 2001; Halkos and Tzeremes 2001)], but no formal theory is available in the literature to the best of my knowledge.

On the empirical front, little is known about the direction of causality in the sizeproductivity nexus at the firm level. While there is a wide literature on the determinants of firm growth in terms of employment (e.g. Henrekson and Johansson 2010; LopezGarcia and Puente 2012), studies analyzing the relationship between productivity and employment growth are scarce and provide contradicting results. Daunfeldt et al. (2010) find that neither high-growth employment is associated to high-growth productivity nor the reverse. They conclude that a trade-off exists between employment and productivity. On the other hand, Du et al. (2013) find that firms which exhibit higher productivity growth are more likely to become high-growth firms in terms of turnover and that high-growth firms are more likely to experience higher productivity growth in the future. Finally, Guillamon et al. (2017) find that high growth in productivity (size) increases the likelihood of high growth in size (productivity) but the magnitude of the effect from size to productivity is smaller than that of the effect from productivity to size.

Using firm-level administrative data for Spain, this paper provides evidence in favor of the hypothesis that firm productivity shocks generate firm growth but not the other way around. In particular, two different treatment variables are considered. First, I consider high-growth in terms of (employment) size as the treatment status and productivity growth as the outcome variable. Second, I consider high-growth productivity as the treatment and employment growth as the outcome. In the baseline specification, high-growth episodes are defined as productivity or employment growth above $10 \%$ in a given year.

I attempt to control for reverse causality and self-selection by using matching techniques that are able to account for observable characteristics but ignore selection on unobservables. Having these concerns in mind, I estimate the effects up to 5 years after each treatment. The estimated effects indicate that high-productivity growth is

\footnotetext{
${ }^{1}$ For instance, Guner et al. (2008) show that size-dependent policies, by preventing most productive firms to grow, can potentially explain a high fraction of the aggregate TFP differences across countries. However, Gourio and Roys (2014), Garicano et al. (2016) and García-Santana and Pijoan-Mas (2014) have found modest effects when evaluating real size-dependent policies in France and India.
} 
followed by statistically significant increases in size/employment growth; in contrast, employment growth is not followed by subsequent gains in productivity. These opposite patterns are reassuring. Selection on unobservables and reverse causality would imply, among other things, the presence of a third omitted factor simultaneously causing subsequent increases in size and TFP. Under this scenario, the positive association between size and TFP growth would show up regardless of which increase (either TFP or size) occurs in the first place. Therefore, I argue that my estimates provide suggestive evidence in favor of the hypothesis that TFP growth causes employment growth but not the other way around. I label this pattern as growing by learning because those firms learning about their higher efficiency levels are those that happen to grow more; under this hypothesis, the process of learning and innovation can be interpreted as the mechanism that makes firms thrive.

Small and unproductive firms are often linked to low productivity growth at the aggregate level (see for instance IMF 2015). It is thus tempting to link the lack of TFP growth in Spain since 1994, as documented by Conesa and Kehoe (2017), with the Spanish firm size distribution biased towards small firms. According to my findings, Spanish firms are small because they are unproductive rather than the other way around. Under this hypothesis, the predominance of small firms is the consequence and not the cause of the low productivity of the Spanish economy. Structural factors, including low $\mathrm{R} \& \mathrm{D}$, low quality of human capital, and elements of the regulatory-legal framework (cost of doing business) that constrain firm productivity growth likely contribute to the dismal evolution of productivity in Spain. ${ }^{2}$

The rest of the article is organized as follows. Section 2 describes the Spanish firmlevel data. Section 3 documents the existence of a positive association between size and productivity at the firm level. Then, Sect. 4 presents the econometric methodology in detail, the main results regarding the growing by learning hypothesis as well as some robustness exercises. Some concluding remarks are provided in Sect. 5.

\section{Data}

I use a firm-level dataset which contains information of a representative sample of Spanish non-financial companies from 2000 to $2007 .{ }^{3}$ The sample contains an average number of 497,782 firms per year. This database is named Central Balance Sheet Data-or Central de Balances Integrada (CBI) in Spanish-and is provided by the Banco de España. This dataset covers not only manufacturing but also services, construction and trade sectors.

\footnotetext{
${ }^{2}$ Needless to say, other factors also contributed to the striking absence of productivity growth during the 1995-2007 Spanish growth experience. For instance, misallocation of capital towards structures rather than capital equipment (Díaz and Franjo 2016), misallocation of capital towards low-productivity firms (Garcia-Santana et al. 2016), and misallocation of credit driven by the real estate bubble (Basco et al. 2018).

${ }^{3}$ I use this sample period because of two reasons: (i) the coverage of the dataset is higher and stable starting in 2000 as illustrated in Fig. 6 in the Appendix. This is so because the Commercial Registry has made a significant effort to facilitate the digital submission of financial statements by firms since the year 2000; (ii) both the Global Financial Crisis and the change in Accounting Rules implemented in 2008 (Plan General de Contabilidad 2007) make it difficult to interpret high growth rates in either productivity or employment around the year 2008 .
} 
The database is comprised of two complementary datasets. The first one-Central de Balances Anual (CBA) - is based on a standardized voluntary survey handled to companies at the time of requesting compulsory accounting information. Each year, around 9000 companies fill this survey. The information gathered is very detailed, but the sample size is low and big firms are over-represented. The second datasetRegistros Mercantiles $(C B B)$ — contains the balance sheets of a much larger number of companies. It originates from the firms' legal obligation to deposit their balance sheets on the Mercantile Registry. Therefore, coverage is much wider.

The Bank of Spain Central Balance Sheet Office is in charge of collecting and cleaning these datasets. All of the variables contained in the latter database are also included in the former. For each firm, I observe its revenue, total wage bill, employment, book value of the capital stock (both physical and intangible), expenses in intermediate goods, and sector of activity at the 4-digit level (according to the NACE rev. 2 classification). Since most of the variables are recorded in nominal terms, I employ sector-specific deflators for capital and value added to compute real values with 2000 as the base year. ${ }^{4}$ Using the information above, I also compute firm-specific measures of total factor productivity (see Sect. 2.1 for details). Finally, for some estimations I also consider the exporter status of each firm taken from the micro data used by the Banco de España to construct the official Spanish Balance of Payments. This dataset, which accounts for 97 per cent of aggregate Spanish exports in 2007, contains information on firms making transactions with foreign agents if they are worth more than $€ 12,000$ and are performed through a bank ( $€ 50,000$ from 2008 on). Ramos and Moral-Benito (2017) provide more information on this dataset.

Despite firms have the legal obligation to submit their statements, some observations are missing from my data because firms deposit their balance sheets late or on paper form, in which case they may not have been digitized. Panel A of Table 1 illustrates the size distribution of firms in my raw sample for the year 2001. The table also compares this distribution with that obtained from the Central Business Register available from the National Statistics Institute, which contains employment information for the universe of Spanish firms. There are two important aspects to highlight. First, the coverage of my raw sample is remarkably large in terms of both the number of firms (56\% of the operating firms in Spain) and the level of employment (54\% of total employment). Second, my sample provides an excellent representation of the firm size distribution in Spain. In particular, small firms (less than 10 employees) account for $83.90 \%$ of the total number of firms and $20.47 \%$ of the employment in my sample versus $83.07 \%$ and $20.23 \%$ in the population. At the other extreme, large firms (more than 200 employees) represent less than $0.5 \%$ of the total number of firms both in my sample and in the population, while they account for $33.47 \%$ of the employment in my sample and $32.13 \%$ in the population.

From this original sample I drop observations with missing or non-positive values for the number of employees, value added, or capital stock. I also eliminate observations at the top and bottom $1 \%$ of these variables. I also exclude firms with 0 employees because these firms represent mostly firms with no production, being created merely

\footnotetext{
4 I take the capital deflators from Mas et al. (2013) and the value added deflator from Spanish National Accounts. Both sets of deflators are constructed at the 2-digit NACE classification.
} 
Table 1 Size distribution of firms in my sample and in the census

\begin{tabular}{|c|c|c|c|c|c|c|c|c|}
\hline \multirow[t]{3}{*}{ Employees } & \multicolumn{4}{|c|}{ Central balance sheet dataset } & \multicolumn{4}{|c|}{ Central business register } \\
\hline & \multicolumn{2}{|l|}{ Firms } & \multicolumn{2}{|l|}{ Labor } & \multicolumn{2}{|c|}{ Firms } & \multicolumn{2}{|l|}{ Labor } \\
\hline & Total (\#) & Share $(\%)$ & Total (\#) & Share $(\%)$ & Total (\#) & Share $(\%)$ & Total (\#) & Share $(\%)$ \\
\hline \multicolumn{9}{|c|}{ Panel A: Raw sample } \\
\hline $0-9$ & 406,924 & 83.90 & 941,897 & 20.47 & 715,795 & 83.07 & $1,718,600$ & 20.23 \\
\hline $10-19$ & 41,664 & 8.59 & 583,312 & 12.68 & 77,372 & 8.98 & $1,050,038$ & 12.36 \\
\hline $20-49$ & 27,125 & 5.59 & 828,714 & 18.01 & 46,683 & 5.42 & $1,400,422$ & 16.49 \\
\hline 50-199 & 8,064 & 1.66 & 707,535 & 15.38 & 17,781 & 2.06 & $1,596,481$ & 18.79 \\
\hline+200 & 1,245 & 0.26 & $1,540,260$ & 33.47 & 4082 & 0.47 & $2,728,958$ & 32.13 \\
\hline All & 485,022 & 100.00 & $4,601,718$ & 100.00 & 861,713 & 100.00 & $8,494,499$ & 100.00 \\
\hline \multicolumn{9}{|c|}{ Panel B: Final sample } \\
\hline $1-9$ & 249,770 & 76.34 & 907,098 & 20.00 & 531,399 & 78.46 & $1,718,600$ & 20.23 \\
\hline $10-19$ & 41,272 & 12.62 & 577,844 & 12.74 & 77,372 & 11.42 & $1,050,038$ & 12.36 \\
\hline $20-49$ & 26,919 & 8.23 & 822,699 & 18.14 & 46,683 & 6.89 & $1,400,422$ & 16.49 \\
\hline 50-199 & 7,984 & 2.44 & 700,565 & 15.44 & 17,781 & 2.63 & $1,596,481$ & 18.79 \\
\hline+200 & 1,219 & 0.37 & $1,528,178$ & 33.69 & 4082 & 0.60 & $2,728,958$ & 32.13 \\
\hline All & 327,164 & 100.00 & $4,536,384$ & 100.00 & 677,317 & 100.00 & $8,494,499$ & 100.00 \\
\hline
\end{tabular}

Figures refer to the year 2001. Self-employed persons are not included

for tax purposes. ${ }^{5}$ I am left with around 350,000 firms per year distributed across 518 4-digit industries. In Panel B of Table 1 I compare this sample to the population of firms in the Central Business Register, from which I have also deleted firms with 0 employees. The screening strategy has minor effects in the distributions of firms and employment, and the representativeness of my final sample remains noticeably good. ${ }^{6}$

\subsection{Measuring firm-level TFP}

In order to obtain firm-level total factor productivity (TFP), I resort to standard estimation techniques, namely, the Wooldridge (2009) GMM approach to implement the Olley and Pakes (1996) and Levinsohn and Petrin (2003) identification strategy.

The object of interest is the TFP of firm $i$ in year $t$, labeled as $a_{i t}$ in the following equation derived from a firm-specific Cobb-Douglas production function:

$$
y_{i t}=\alpha_{L} l_{i t}+\alpha_{K} k_{i t}+\alpha_{M} m_{i t}+a_{i t}
$$

where $y$ refers to logged revenue, and $l, k$, and $m$ are logged labour, capital, and materials, respectively.

\footnotetext{
5 Notice that these firms are not self-employed people, which are not covered in out dataset.

6 This is true for all years between 2000 and 2007 as illustrated in Fig. 6 in the Appendix.
} 
Note that the measure of TFP identified in Eq. (1) is revenue productivity, which is expected to be equal across firms within each industry under the assumption of frictionless markets (see e.g. Hsieh and Klenow 2009). In this setting, heterogeneity in our firm-level TFPs should be attributed to heterogeneity in firm-specific wedges due to, for instance, variable markups or idiosyncratic distortions. However, revenue productivity provides a meaningful measure of TFP if these wedges are positively correlated with productivity as suggested by Bento and Restuccia (2017) for Spain.

The estimation of Eq. (1) is performed on a 2-digit industry level. However, in order to obtain consistent estimates with sufficient degrees of freedom, a cutoff of a minimum of 25 observations per sector and year is introduced. Sectors that do not meet the minimum cutoff are flagged and their TFP estimates are replaced by an estimated value obtained on the corresponding macro-sector level. A full set of year dummies in each sector-specific regression is included to control for sector-specific trends.

To estimate the parameters in the production function, I assume that $a_{i t}$ is the sum of two firm-specific and unobserved components, namely, a component which is known to the firm $\left(\omega_{i t}\right)$, and a component unknown to the firm and with no impact on firm's decisions $\left(v_{i t}\right)$. The endogeneity problem that renders OLS estimates biased when estimating Eq. (1) arises from the correlation of $\omega_{i t}$ with the input choices. One of the solutions provided for solving this problem is introduced by Olley and Pakes (1996) who proposed a structural approach to the problem, by using observed input choices to instrument for unobserved productivity. In particular, their approach relied upon the assumption that investment, $i_{i t}$, installed in period $t$ only becomes productive at $t+1$, so that $i_{i t}=i\left(\omega_{i t} ; k_{i t}\right)$ can be inverted to yield $\omega_{i t}=\omega\left(i_{i t} ; k_{i t}\right)$ under the assumption of increasing monotonicity of $i_{i t}$ in $\omega_{i t}$.

Levinsohn and Petrin (2003) argued that the strict monotonicity of the investment function was broken given the many zeros reported by firms. If all observations with zero or negative investment had to be dropped, there would be an important efficiency loss in the estimation. Therefore, Levinsohn and Petrin (2003) advocate to invert the materials' demand function $m_{i t}=m\left(\omega_{i t} ; k_{i t}\right)$ to obtain $\omega_{i t}=\omega\left(m_{i t} ; k_{i t}\right)$, also under monotonicity plus some additional assumptions. Finally, Wooldridge (2009) introduces an appealing GMM approach that implements this identification strategy reducing the computational burden as well as producing more efficient estimates.

\section{The size-productivity nexus}

Small firms are less productive than larger ones. Table 2 confirms this fact for my sample of Spanish firms. Relative to the firms with 1-9 employees, firms with more than 250 employees are roughly $1.83 \log$ points more productive (i.e. 208 per cent more productive) according to the figures in Column (1). This figure implies a TFP ratio of $e^{1.83}=6.23$, which indicates that the average firm with more than 250 employees makes around six times as much output with the same measured inputs as the average firm with 1-9 employees. Also, firms with between 50 and 249 employees are roughly 
Table 2 Average productivity by size class

\begin{tabular}{lllllll}
\hline Size class & $\begin{array}{l}\text { Overall } \\
(1)\end{array}$ & $\begin{array}{l}\text { Overall } \\
(2)\end{array}$ & $\begin{array}{l}\text { Manufacturing } \\
(3)\end{array}$ & $\begin{array}{l}\text { Construction } \\
(4)\end{array}$ & $\begin{array}{l}\text { Trade } \\
(5)\end{array}$ & $\begin{array}{l}\text { Services } \\
(6)\end{array}$ \\
\hline $1-9$ & 0.88 & 1.10 & 1.03 & 0.55 & 1.02 & 0.81 \\
$10-19$ & 1.24 & 1.46 & 1.38 & 0.86 & 1.36 & 1.29 \\
$20-49$ & 1.48 & 1.68 & 1.61 & 1.09 & 1.55 & 1.58 \\
$50-249$ & 1.81 & 2.01 & 2.09 & 1.37 & 1.86 & 1.71 \\
+250 & 2.71 & 2.84 & 3.02 & 2.51 & 2.68 & 2.34 \\
Dummies & No & Yes & No & No & No & No \\
\hline
\end{tabular}

Figures refer to average log total factor productivity (TFP) measured at the firm level as described in Sect. 2.1. Dummies refer to the inclusion of 2-digit industry and year dummies in a regression of $\log$ TFP on a set of size dummies. The sample covers the period 2000-2007

105 per cent more productive than firms with between 1 and 9 employees, implying a TFP ratio of 2.5. Finally, firms with 20-49 and 10-19 employees are 67 and 41 per cent more productive than firms with 1-9 employees, which implies TFP ratios of 1.80 and 1.43 , respectively. These differences cannot be explained by differences in the size distribution of firms across industries or years since they remain very similar when I regress log TFP on a set of size dummies accounting for 2-digit industry and year dummies in Column (2). Finally, Columns (3)-(6) report the same figures for each main sector of activity confirming the patterns discussed above.

In addition to the descriptive statistics reported in Table 2, the size-productivity nexus is also illustrated by the correlation between log employees and log TFP, which is 0.33 (t-stat $=12.59$ ). This correlation remains positive, large, and statistically significant when I account for a set of industry and year dummies: 0.32 with t-stat $=$ 23.34. I next compute the quintiles of TFP and size by industry and year confirming that firms in higher quintiles of TFP tend to be in higher quintiles of size. For instance, around $40 \%$ of the firms in the first quintile of TFP belong to the first size quintile while only $5 \%$ belong to the fifth size quintile. These figures imply that among the $20 \%$ most productive firms, $40 \%$ are also among the largest $20 \%$ while only $5 \%$ are among the smallest $20 \%$.

Figure 1 illustrates that the whole distribution of productivity is shifted to the right for large firms, which implies that average figures reported above are not driven by a handful of outliers. Moreover, dispersion seems to be larger in the group of firms with more than 50 employees. This pattern is also documented by Farinas et al. (2015) for a sample of OECD countries using the OECD compendium of productivity indicators (see Figure 5.1 in Farinas et al. 2015).

Finally, Appendix A documents the excess of small and low-productivity firms active in Spain in comparison with the rest of EU4 countries. Crucially, the evidence presented in Appendix A uncovers that Spanish firms are less productive than their European counterparts for all size categories. Moreover, Appendix B reviews some available evidence in the literature pointing to poor managerial talent, low quality of the labor input, and scarce R\&D activities as key factors at the root of the dismal performance in terms of productivity of Spanish firms. 


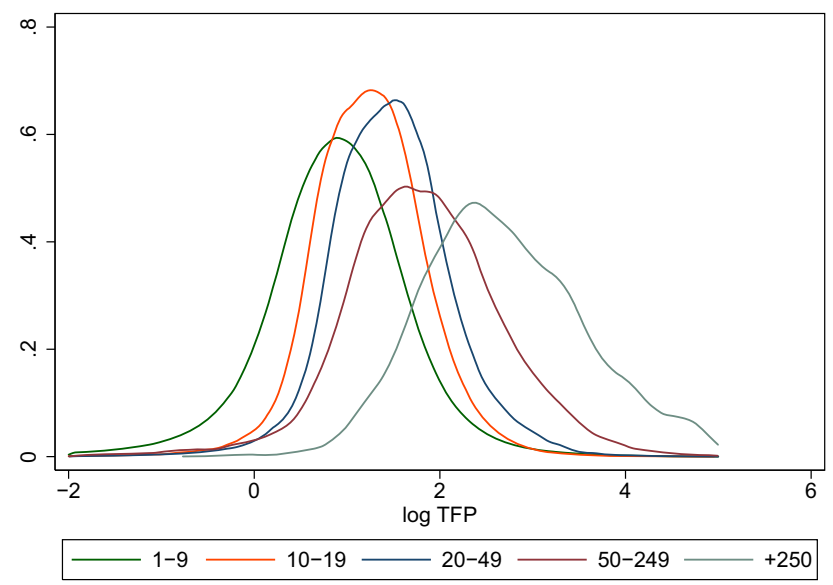

Fig. 1 Distribution of productivity by size class in Spain. Notes This figure plots the distribution of log TFP of Spanish firms over the period 2000-2007 by size class. The five size categories reported are: (1) from 1 to 9 employees; (2) from 10 to 19 employees; (3) from 20 to 49 employees; (4) from 50 to 249 employees; (5) more than 250 employees. The distribution is estimated by means of an epanechnikov kernel function using the optimal bandwidth that minimizes the mean integrated squared error

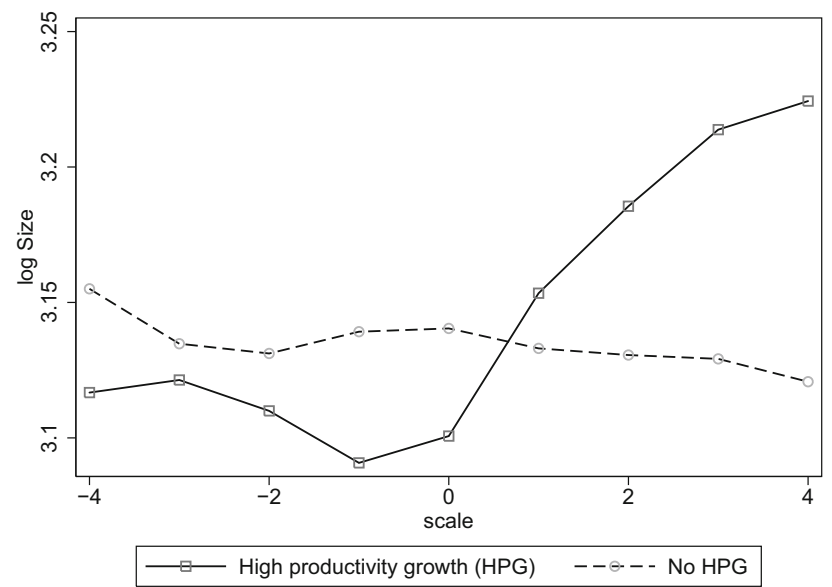

Fig. 2 TFP shock at $s=0$ and subsequent size growth. Notes HPG firms are those with TFP growth above $10 \%$ in 2003, labeled as $s=0$. The remaining firms are labeled as "No HPG" in the same year. The vertical axis plots average log size for these two different groups before and after 2003

\section{Growing by learning versus learning by growing}

In order to graphically inspect whether firms grow once they enjoy a positive productivity shock, Fig. 2 plots on the horizontal axis a time scale which is zero for the period where firms are hit by the productivity shock. These firms are labeled as High Productivity Growth (HPG). To be more concrete, HPG firms are those with TFP growth 
above $10 \%$ in 2003 , which roughly corresponds to the 85 th percentile in this year. ${ }^{7}$ The remaining firms are labeled as "No HPG" in the same year. On the vertical axis I plot average log size for these two different groups before and after 2003. We can see that after 4 years firms hit by a TFP shock are $17 \%$ larger. In contrast, firms in the control group are slightly smaller over the same 4 years. Moreover, Fig. 2 illustrates than HPG firms are smaller than non-HPG firms before they receive the shock but become larger afterward.

I label the pattern depicted in Fig. 2 as growing by learning because those firms learning how to improve their production strategies are those that happen to grow more; under this hypothesis, the process of learning and innovation can be interpreted as the mechanism that makes firms thrive. Indeed, the growing by learning hypothesis is implicitly assumed in theoretical models of firm dynamics that characterize industries as groups of heterogeneous-productivity firms (e.g. Jovanovic 1982; Melitz 2003). These models assume that firms learn about their productivity as they operate in the market. Low productivity firms are less likely to survive and thrive than their more efficient counterparts. Learning by growing represents an alternative rationale to explain the size-productivity nexus. This label resembles the learning by doing terminology used in earlier papers supporting the view that productivity rises with cumulative experience proxied by firm size (see for instance Rapping 1965).

Despite the suggestive evidence in favor of the growing by learning hypothesis in Fig. 2, HPG firms may be hit by an omitted shock in 2003 simultaneously causing the high productivity growth as well as subsequent increases in size. The remaining of the paper formally tests this hypothesis simultaneously accounting for selection on observables and endogeneity by combining matching methods with a bi-directional identification strategy that I next describe.

\subsection{Econometric approach}

I test for the growing by learning (GBL) and learning by growing (LBG) hypotheses by creating control groups using matching techniques based on average treatment models as discussed in Heckman et al. (1997). The intuition of this technique is to estimate the effect of productivity (size) growth on size (productivity) growth by matching high-growth-productivity (-size) firms with non-high-growth-productivity (size) firms. The method constructs a counterfactual which allows analyzing how size (productivity) of a firm would have evolved if it had not received a productivity (size) shock. This counterfacual is based on matching the high-growth-productivity (size) firm with a control group of similar characteristics that do not receive the productivity (size) shock.

I consider two parallel empirical specifications throughout this section: (i) one in which the treatment variable is a productivity shock and the outcome of interest is size growth (growing by learning-GBL); (ii) another one in which the treatment status is

\footnotetext{
7 I choose 2003 as the base year in order to consider a permanent sample of firms with 4 observations available before and after 2003 for each one.
} 
defined by a size/employment shock and the outcome variable is productivity growth (learning by growing-LBG).

In order to formally introduce the approach, I first rescale the time periods in such a way that a firm receives the productivity (size) shock at $s=0 .{ }^{8}$ Let $y_{i s}$ be the outcome at time $s$ - either productivity growth or size growth-of firm $i$ at period $s$. The variable $H G F_{i}$ takes the value one if a firm $i$ receives a productivity (or size) shock at $s=0$. In the baseline estimation, a firm is labeled as a high-growth firm if its productivity (or size) growth is above the 75th percentile, which roughly corresponds to an annual growth rate above $10 \%$ in both cases. ${ }^{9}$ On the other hand, I follow the literature of gazelles and high-growth companies and I restrict the sample to firms with more than 10 employees in order to reduce the over-representation of small firms in the group of high-growth firms. ${ }^{10}$ Finally, identified high-growth firms are excluded from the control group in all periods, and only the first high-growth episode for each firm is considered as a treatment in order to avoid overlapping.

The causal effect can be verified by looking at the average effect of interest:

$$
E\left(y_{i s}^{1}-y_{i s}^{0} \mid H G F_{i}=1\right)=E\left(y_{i s}^{1} \mid H G F_{i}=1\right)-E\left(y_{i s}^{0} \mid H G F_{i}=1\right)
$$

where the superscript denotes whether firm $i$ received a shock at $s=0$ or not. In particular, $y_{i s}^{1}$ is the outcome if firm $i$ receives a shock while $y_{i s}^{0}$ denotes the outcome of firm $i$ if it does not receive the shock. Therefore, the crucial problem in this analysis is that the second term in Eq. (2) is not observable. This is the effect that high-growth firms would have experienced, on average, had they not received the shock. In order to identify this term I assume that all differences between high-growth firms and the appropriate control group can be captured by a vector of observables including the pre-shock size and productivity of a firm. For that purpose, I apply the propensity score matching method (see Rosenbaum and Rubin 1983) ${ }^{11}$ which provides me with an appropriate control group that is as close as possible to the high-growth firm in terms of its predicted probability to receive a high growth/productivity shock.

To be more concrete, I model the probability of becoming a high-growth firm (the propensity score) as follows:

$$
\operatorname{Pr}\left(H G F_{i, 0}=1\right)=\Phi\left[h\left(y_{i,-1}, X_{i,-1}\right)\right]
$$

$\Phi(\cdot)$ refers to the normal cumulative distribution function. The subscript -1 denotes that the probability of being a high-growth firm is regressed on variables prior to

\footnotetext{
${ }^{8}$ I follow the strategy proposed by De Loecker (2007) when estimating the productivity gains of exporting.

9 A widely used definition of high-growth firms establishes that average employment growth must exceed $20 \%$ per year over a 3 -year period and the firm must have 10 or more employees at the start of the period (see for instance Henrekson and Johansson 2010). I do not consider this type of multi-period definition because the balancing hypothesis is not satisfied when using this criterion as explained below.

10 For instance, in the case of the $10 \%$ annual employment growth corresponding to the 75 th percentile in my sample, all firms with 1-9 employees would be labeled as high-growth firms as long as they increase their size in one single employee.

11 This method boils down to estimating a probit model with a dependent variable equal to 1 if a firm is a high-growth firm and zero elsewhere on lagged observables.
} 
$s=0$. I take a full polynomial in the elements of $h(\cdot)$ as to free up the functional form and improve the resulting matching (Wooldridge 2002). The lagged outcome variable $y_{i,-1}$ is included as a pre-treatment control together with other relevant firmlevel covariates, namely, total factor productivity, size, export status, wages, and age. Finally, I estimate the propensity score by year and 2-digit NACE industry to control for common aggregated demand and supply shocks. Let the predicted high-growth firm probability be denoted by $p_{i} .{ }^{12}$

The matching is based on the method of the nearest neighbor, which selects a nonhigh-growth firm $j$ which has a propensity score $p_{j}$ closest to that of the corresponding high-growth firm (Becker and Ichino 2002 provide more details on this matching procedure). More concretely, I match within each year and 2-digit NACE sector and therefore create control groups within narrowly defined sectors. This matching strategy results in a group of matched HGF and non HGF firms that allows me to evaluate the causal impact of (i) productivity shocks on size growth, and, (ii) size shocks on productivity growth.

Having established a matched sample of treated (HGF) and control (non HGF) firms, I use a difference-in-differences (DID) methodology to estimate the effects of interest. In particular, every HGF firm $i$ is matched with a group of $N_{i}^{c}$ control firms denoted as $C(i)$. The weight of each control firm in the group of controls for the treated firm $i$ is given by $w_{i j}=\frac{1}{N_{i}^{c}}$ if $j \in C(i)$ and zero otherwise. Moreover, I define $y^{1}$ and $y^{c}$ as the estimated outcomes of the treated and the controls, respectively. Armed with these ingredients, I consider the following estimator in the spirit of De Loecker (2007):

$$
\beta_{h}^{s}=\frac{1}{N_{s}} \sum_{i}\left(y_{i s}^{1}-\sum_{j \in C(i)} w_{i j} y_{j s}^{c}\right)
$$

where $h$ denotes the hypothesis being tested, either growing by learning effect ( $h=$ $G B L)$ or learning by growing effect $(h=L B G)$. In the case $h=G B L$, the matching is performed considering as HGF firms those with high productivity growth while the matching is based on high size growth firms for the case $h=L B G$. In both cases, the matching is performed at the time a firm receives the shock and $s=1, \ldots, S$ denotes the time periods after the shock $(s=0)$. Therefore, $\beta_{h}^{s}$ estimates the effect at every period $s$ after the shock. The outcome variable of interest, $y_{i s}$, can be either productivity growth or size growth.

In addition to the impact effect estimated by $\beta_{h}^{s}$, I also consider the cumulative effect gathered over a period $S$ after the shock:

$$
\beta_{h}^{S}=\frac{1}{N_{S}} \sum_{i}\left(\sum_{s=0}^{S} y_{i s}^{1}-\sum_{s=0}^{S} \sum_{j \in C(i)} w_{i j} y_{j s}^{c}\right)
$$

$\overline{12}$ The balancing hypothesis states that for a given propensity score $p_{i}$, exposure to treatment is random and thus treated and control units should be on average observationally identical. In order to corroborate that this assumption is satisfied in my application, I perform the algorithm described in Becker and Ichino (2002). 
Table 3 Estimated GBL and LBG effects

\begin{tabular}{|c|c|c|c|c|c|}
\hline$s$ & 1 & 2 & 3 & 4 & 5 \\
\hline \multicolumn{6}{|c|}{ (a) Outcome: employment growth } \\
\hline \multirow[t]{2}{*}{$\beta_{G B L}^{s}$} & $0.017^{* * *}$ & $0.012^{* * *}$ & $0.010^{* *}$ & 0.004 & 0.003 \\
\hline & $(0.004)$ & $(0.004)$ & $(0.005)$ & $(0.007)$ & $(0.006)$ \\
\hline \multicolumn{6}{|c|}{ (b) Outcome: cumulative employment growth } \\
\hline \multirow{2}{*}{$\beta_{G B L}^{S}$} & $0.017^{* * *}$ & $0.037^{* * *}$ & $0.045^{* * *}$ & $0.075^{* * *}$ & $0.084^{* * *}$ \\
\hline & $(0.004)$ & $(0.005)$ & $(0.006)$ & $(0.007)$ & $(0.009)$ \\
\hline \multicolumn{6}{|c|}{ (c) Outcome: productivity growth } \\
\hline \multirow[t]{2}{*}{$\beta_{L B G}^{S}$} & $0.017^{*}$ & -0.005 & -0.014 & -0.008 & -0.010 \\
\hline & $(0.009)$ & $(0.005)$ & $(0.020)$ & $(0.009)$ & $(0.014)$ \\
\hline \multicolumn{6}{|c|}{ (d) Outcome: cumulative productivity growth } \\
\hline \multirow[t]{2}{*}{$\beta_{L B G}^{S}$} & $0.017^{*}$ & 0.012 & 0.006 & 0.012 & 0.007 \\
\hline & $(0.009)$ & $(0.012)$ & $(0.017)$ & $(0.008)$ & $(0.031)$ \\
\hline
\end{tabular}

$s=1, \ldots, 5$ denotes the time periods after the shock that takes place as $s=0$. The number of treated firms is 5502 and the number of controls is 14,135 in rows (a) and (b). In rows (c) and (d) the number of treated firms is 5697 and the number of controls is 12,533 . I denote significance at 10,5 and $1 \%$ with *, ** and $* * *$, respectively. Standard errors are denoted in parentheses

In words, $\beta_{h}^{S}$ in Eq. (5) measures the productivity/size gains that HGF firms gather over $S$ periods whereas $\beta_{h}^{s}$ in Eq. (4) estimates the gain at each period $s$.

\subsection{Baseline results}

The estimated growing by learning (GBL) and learning by growing (LBG) effects are reported in Table 3. Rows (a) and (b) refer to the growing by learning hypothesis. In row (a) I present the impact of a productivity shock on employment growth at every period $s$, whereas row (b) shows the cumulative employment growth effect, reflecting the size growth premium gathered after $S$ periods. Rows (c) and (d) refer to the learning by growing hypothesis. Row (c) presents the estimated impact of an employment shock on productivity growth at every period $s$ after the shock, whereas row (D) reports the corresponding cumulative effects.

Rows (a) and (b) illustrate that a productivity shock has a positive and significant treatment effect on size growth, which provides evidence in favour of the growing by learning hypothesis. High-productivity-growth firms grow on average $1.7 \%$ more the year after they increase their productivity $(s=1)$. This figure is reduced to 1.2 and $1.0 \%$ in the second and third years, respectively. The effect on size growth is no longer significantly estimated after 4 years of receiving the productivity shock.

With respect to the GBL cumulative effects, row (b) shows that after 5 years $(s=5)$, employment growth of high-productivity-growth firms is on average $8.4 \%$ higher than non-HPGF firms. According to these results, a productivity shock at $s=0$ causes cumulative size growth to be significantly higher even after 5 years $(s=5)$. Note that the estimated cumulative effects $\beta_{h}^{S}$ are not equal to the sum of the pure time effects $\beta_{h}^{S}$ due to the unbalanced data, i.e., $\sum_{s} \beta_{h}^{s} \neq \beta_{h}^{S}$ since $N$ varies with $s$. 

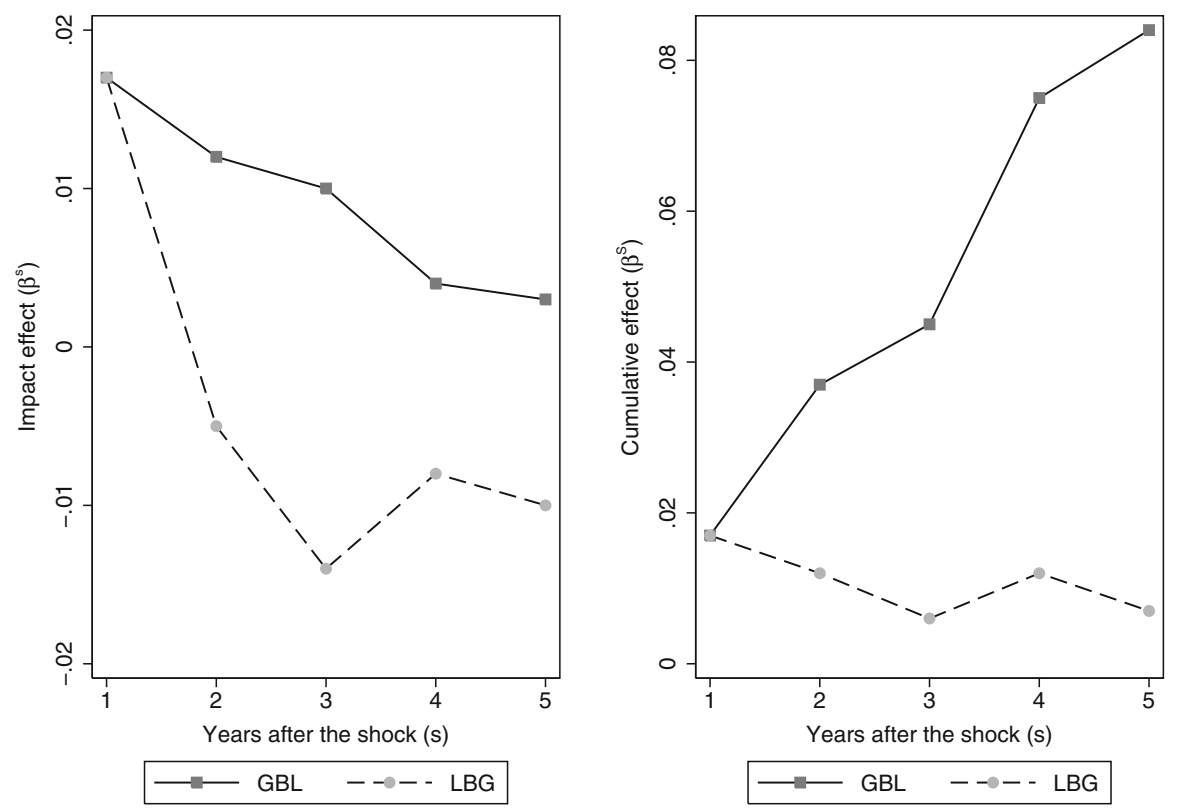

Fig. 3 Estimated GBL and LBG effects. Notes. The solid line plot the estimated growing by learning (GBL) effects. The dashed line plots the learning by growing (LBG) effects. The left panel shows the cumulative effect $\left(\beta_{h}^{S}\right)$ on either employment (GBL) or productivity (LBG) growth while the right panel shows impact effects $\left(\beta_{L B G}^{S}\right)$

The economic magnitude of the estimated GBL effects is also relevant. Consider two identical firms, A and B, with 60 employees. In a given year $(s=0)$, firm A receives a productivity shock while firm B does not. According to the estimates in Table 3, the next year $(s=1)$ firm A will hire an additional worker while firm B will not. After 5 years $(s=5)$, firm A will hire five additional workers but firm B will not.

Turning to the LBG estimated effects in rows (c) and (d) of Table 3, they provide little support for the learning by growing hypothesis. To be more concrete, row (c) shows the impact effects of an employment shock on productivity growth at every period. In the first year $(s=1)$ the estimated LBG effect is very similar to the GBL effect in row (a) but it is less precisely estimated being significant only at the $10 \%$ level. However, the impact LBG effect vanishes after 1 year becoming even negative albeit not statistically significant.

The cumulative LBG effects reported in row (d) confirm that productivity growth does not increase after an employment shock. While there is a positive effect during the first year, it is only significant at the $10 \%$ level. ${ }^{13}$ In any event, the effect of employment growth on cumulative productivity growth is not statistically significant after the first year, which confirms that size growth cause no effect on productivity growth.

Finally, Fig. 3 illustrates the main findings. The estimated impact and cumulative GBL_ - growing by learning — effects are positive during 5 years after the shock.

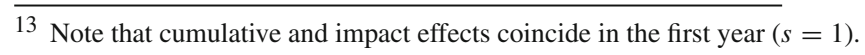


In particular, the impact GBL effect is decreasing while the GBL cumulative effect increases over time. In contrast, the learning by growing (LBG) effects are even negative on impact and roughly zero in cumulative terms.

I interpret these opposing findings as evidence that productivity growth does cause firm growth, whereas firm growth does not cause productivity growth. The identification assumptions required for a causal interpretation of the GBL effects alone might be controversial. This is so because I can only make firms comparable in terms of the observable characteristics included in the propensity score, while they might well differ in other non-observable dimensions, i.e., I can account for selection on observables but not for selection on unobservables. Analogously, the same concern applies to the causal interpretation of the LBG effects. The fact that the effect is positive and significant only in one direction (from productivity to size growth) indicates that the causal interpretation of my GBL estimates is not sharply at odds with the data.

\subsection{Robustness analysis}

In this section I perform several robustness exercises. In particular, these robustness checks are related to the definition of high-growth firms, the presence of systematic differences before the shock (pre-trends), the matching methodology and the inclusion of financial variables. First, in the baseline a firm is labeled as a high-growth firm if its productivity (or size) growth is above an annual growth rate above $10 \%$, which roughly corresponds to the 75th percentile. Second, in the baseline the matching is based on the method of the nearest neighbor, which selects the non-high-growth firms with the closest propensity score. I consider in Sect. 4.3.1 different definitions of highgrowth firms as well as different matching techniques in Sect. 4.3.2 to investigate the robustness of the baseline results. In Sect. 4.3.3 I consider a permanent sample (balanced panel) to investigate if my baseline estimates are robust to attrition, and I check for the the presence of common trends in the treatment and control groups before the treatment takes place (pre-trends). In Sect. 4.3.4 I re-estimate the baseline specification and consider the asymptotic standard errors derived in Abadíe and Imbens (2016), which take into account the estimation error in the propensity score. Also, I include the firms' cash-flow among the control variables in the matching to ensure that differences in firm's liquidity do not bias the baseline estimates.

\subsubsection{Alternative HGF definitions}

The criterion for defining a high-growth firm (in terms of both size and productivity) determines the treatment and control groups. Therefore, it represents an assumption that might have non-negligible effects on the estimates. In my baseline results HGF firms are those with productivity (or size) annual growth above $10 \%$ that result in a control and treatment groups satisfying the balancing hypothesis. ${ }^{14}$ Standard defini-

\footnotetext{
14 In particular, this assumption requires that for a given propensity score $p_{i}$, exposure to treatment is random and thus treated and control units should be on average observationally identical (see Becker and Ichino 2002).
} 
Table 4 Estimated GBL and LBG effects-robustness (I)

\begin{tabular}{|c|c|c|c|c|c|}
\hline$s$ & 1 & 2 & 3 & 4 & 5 \\
\hline \multicolumn{6}{|c|}{ Panel A: Effect of productivity on cumulative size growth $\left(\beta_{G B L}^{S}\right)$} \\
\hline \multirow[t]{2}{*}{ HGF $8 \%$} & $0.022 * * *$ & $0.037^{* * *}$ & $0.040^{* * *}$ & $0.057^{* * *}$ & $0.076^{* * *}$ \\
\hline & $(0.004)$ & $(0.005)$ & $(0.006)$ & $(0.007)$ & $(0.009)$ \\
\hline \multirow[t]{2}{*}{ HGF $12 \%$} & $0.025^{* * *}$ & $0.042^{* * *}$ & $0.054^{* * *}$ & $0.073^{* * *}$ & $0.067^{* * *}$ \\
\hline & $(0.004)$ & $(0.004)$ & $(0.005)$ & $(0.006)$ & $(0.008)$ \\
\hline \multirow[t]{2}{*}{ HGF only TFP } & $0.046^{* * *}$ & $0.057^{* * *}$ & $0.056^{* * *}$ & $0.066^{* * *}$ & $0.089^{* * *}$ \\
\hline & $(0.007)$ & $(0.005)$ & $(0.007)$ & $(0.008)$ & $(0.009)$ \\
\hline \multicolumn{6}{|c|}{ Panel B: Effect of size on cumulative productivity growth $\left(\beta_{L B G}^{S}\right)$} \\
\hline \multirow[t]{2}{*}{ HGF $8 \%$} & $0.012^{* *}$ & 0.001 & $-0.015^{*}$ & -0.015 & -0.011 \\
\hline & $(0.005)$ & $(0.006)$ & $(0.008)$ & (0.009) & $(0.010)$ \\
\hline \multirow[t]{2}{*}{ HGF $12 \%$} & 0.012 & 0.022 & 0.004 & $0.021^{*}$ & 0.003 \\
\hline & $(0.012)$ & $(0.016)$ & $(0.024)$ & $(0.011)$ & $(0.039)$ \\
\hline \multirow[t]{2}{*}{ HGF only size } & $0.015^{*}$ & $0.015^{*}$ & 0.004 & 0.006 & 0.013 \\
\hline & $(0.008)$ & (0.009) & $(0.011)$ & $(0.012)$ & $(0.014)$ \\
\hline
\end{tabular}

$s=1, \ldots, 5$ denotes the time periods after the shock that takes place as $s=0$. HGF $8 \%$ refers to highgrowth firms defined as those with TFP (or size) growth above $8 \%$ in a given year, which corresponds to the 70 th percentile in the sample. HGF $12 \%$ identifies firms with TFP (or size) growth above $12 \%$, the 80 th percentile. HGF only TFP (size) refer to high-growth firms in terms of productivity (size) but not in terms of size (productivity) — see the main text for more details. I denote significance at 10,5 and $1 \%$ with *, ** and ${ }^{* * *}$, respectively. Standard errors are denoted in parentheses

tions of high-growth firms (HGF) in terms of employment are based on multi-period criteria more stringent than the one in my baseline estimates. For instance, the OECD labels as HGF a firm with average employment growth above $20 \%$ per year over a 3-year period; also, the firm must have 10 or more employees. I cannot consider this type of definition because the resulting groups of treated and control firms do not satisfy the the balancing hypothesis, which is crucial for ensuring the validity of the matching estimates. Therefore, for the robustness exercises I consider two alternative definitions with alternative thresholds for the annual growth rate (in terms of both productivity-GBL—and employment- $\mathrm{LBG}-$ ). In particular, I consider thresholds of 8 and $12 \%$ which roughly correspond to the 70 th and 80 th percentiles, respectively.

Table 4 shows the estimated GBL and LBG effects in cumulative terms under the labels HGF 8 and HGF $12 \%$. As in the baseline results, GBL effects are highly significant and present similar magnitudes. If if consider a threshold above $12 \%$ (such as $20 \%$, which corresponds to the 90th percentile), the balancing hypothesis is not satisfied. Thresholds below $8 \%$ (e.g. 4\%) correspond to lower percentiles (around 55th) so that the identification of a size/productivity shock is less clear-cut and the HGF labeling becomes more controversial. ${ }^{15}$

\footnotetext{
15 In any event, the main results remain robust when using the $4 \%$ threshold and are available upon request.
} 
The overlapping between HGF in size and productivity represents another concern related to the definition of high-growth firms. In particular, $18 \%$ of high-growth firms in terms of productivity are also high-growth firms in terms of size. Analogously, $16 \%$ of HGF in size are also HGF in productivity. Therefore, the productivity (size) shock considered in the baseline specification might include a size-(productivity-) shock component. In other words, around one sixth of the firms experiencing a productivity (size) shock also enjoy a size (productivity) shock, which might contaminate the baseline estimates of the GBL and LBG effects. Table 4 reports GBL and LBG effects estimated from a sample that does not include firms that are HGF in terms of both TFP and size. The GBL estimates are even larger in magnitude while the LBG remain statistically insignificant after the second period, which corroborates the robustness of the baseline estimates to different definitions of high-growth firms.

\subsubsection{Alternative matching techniques}

The particular technique considered for matching control and treated firms might also represent a decision with significant effects on the results. In the baseline estimates, I consider the method of the nearest neighbor as explained in Sect. 4.1. Two alternative methods are explored in the robustness exercises, kernel and stratification matching. None of the different techniques is ex-ante superior to the others given the the trade-off between quality and quantity of the matches, but their joint consideration allows me to assess the robustness of the estimates. Dehejia and Wahba (2002) provide more details on the different matching methods based on the propensity score.

First, I consider kernel matching in which all treated firms are matched with a weighted average of all controls using weights that are inversely proportional to the distance between the propensity scores of treated and controls. In the nearest neighbor method considered in the baseline, for some treated units the nearest neighbor may have a very different propensity score, and, nevertheless, it would contribute to the estimation of the treatment effect independently of this difference. This caveat is addressed by the weighting scheme considered in kernel matching. Second, I consider the stratification method that consists of dividing the propensity score in intervals such that within each interval, treated and control units have on average the same propensity score. Then, within each interval the difference between the average outcomes of the treated and the controls is computed. The overall effect is obtained as an average of the effects for each block with weights given by the distribution of treated units across blocks. Note that with this method, some treated units may be discarded in case no control is available in their block.

Table 5 reports the cumulative GBL and LBG effects estimated when using Kernel and Stratification matching techniques. In the case of GBL cumulative effects in Panel A, the estimates are highly significant and very similar to those in the baseline results based on nearest neighbor matching [see row (b) of Table 3]. Turning to the LBG results in Panel B, the estimated effects are more precisely estimated than those in the baseline results for the first 2 years after the size shock $(s=1$ and $s=2)$. However, the effects completely vanish after the third period $(s=3)$ as in row (d) of 
Table 5 Estimated GBL and LBG effects-robustness (II)

\begin{tabular}{|c|c|c|c|c|c|}
\hline$s$ & 1 & 2 & 3 & 4 & 5 \\
\hline \multicolumn{6}{|c|}{ Panel A: Effect of productivity on cumulative size growth $\left(\beta_{G B L}^{S}\right)$} \\
\hline \multirow[t]{2}{*}{ Kernel matching } & $0.020^{* * *}$ & $0.040^{* * *}$ & $0.057^{* * *}$ & $0.073^{* * *}$ & $0.081^{* * *}$ \\
\hline & $(0.002)$ & $(0.004)$ & $(0.009)$ & $(0.010)$ & $(0.010)$ \\
\hline \multirow[t]{2}{*}{ Stratification matching } & $0.015^{* * *}$ & $0.035^{* * *}$ & $0.042^{* * *}$ & $0.070^{* * *}$ & $0.079^{* * *}$ \\
\hline & $(0.003)$ & $(0.005)$ & $(0.007)$ & $(0.008)$ & $(0.010)$ \\
\hline \multicolumn{6}{|c|}{ Panel B: Effect of size on cumulative productivity growth $\left(\beta_{L B G}^{S}\right)$} \\
\hline \multirow[t]{2}{*}{ Kernel matching } & $0.018^{* * *}$ & $0.019^{* *}$ & 0.001 & 0.006 & 0.002 \\
\hline & $(0.004)$ & $(0.008)$ & $(0.007)$ & $(0.009)$ & $(0.010)$ \\
\hline \multirow[t]{2}{*}{ Stratification matching } & $0.021^{* * *}$ & $0.022^{* *}$ & 0.003 & 0.008 & 0.009 \\
\hline & $(0.003)$ & $(0.009)$ & $(0.008)$ & $(0.009)$ & $(0.011)$ \\
\hline
\end{tabular}

$s=1, \ldots, 5$ denotes the time periods after the shock that takes place as $s=0$. Kernel and stratification matching refer to alternative techniques for constructing the control group (see the main text for more details). I denote significance at 10, 5 and $1 \%$ with ${ }^{*},{ }^{* *}$ and ${ }^{* * *}$, respectively. Standard errors are denoted in parentheses

Table 3 based on nearest neighbor matching. All in all, I conclude that the matching technique considered in the baseline results has no decisive impact on the estimated effects.

\subsubsection{Pre-trends and attrition bias}

Firms assigned to the treatment and control groups may systematically differ in the evolution of size/productivity growth even before the identified shock takes place at $s=0$. If this is so, the estimated effects would be the result of some trends previous to the high-growth episode rather than a consequence of the high-growth shock per se. In order to rule out this possibility, I re-estimate Eq. (5) by substituting size/productivity growth after the shock (the $y_{i s}$ variables) by size/productivity growth before the shock. In particular, $y_{i s}$ is now productivity/size growth $s$ periods before the shock for firm $i$.

On the other hand, the estimated differences between the treatment and control groups may be due to attrition bias. To the extent that survival probabilities are likely to differ between treated and control firms, differences in the composition of the treatment and control groups could bias the estimated effects. In order to further investigate this possibility, I re-estimate the baseline specification in Eq. (5) on a permanent sample (balanced panel) of firms active all years.

Table 6 presents the estimates for both exercises. The estimates in rows 1 and 3 (permanent sample) confirm that the main findings remain unaltered when considering a balanced panel in which treated and control firms are the same in all periods after the shock so that attrition bias is accounted for. Turning to pre-trends, results in rows 2 and 4 confirm that the differences in size/productivity growth between treated and control firms before the shock at $s=0$ are not statistically different from zero, which corroborates that firms in both groups were observationally equivalent before the treatment. 
Table 6 Estimated GBL and LBG effects-robustness (III)

\begin{tabular}{|c|c|c|c|c|c|}
\hline$s$ & 1 & 2 & 3 & 4 & 5 \\
\hline \multicolumn{6}{|c|}{ Panel A: Effect of productivity on cumulative size growth $\left(\beta_{G B L}^{S}\right)$} \\
\hline \multirow[t]{2}{*}{ Permanent sample } & $0.035^{* * *}$ & $0.030^{* * *}$ & $0.056^{* * *}$ & $0.082^{* * *}$ & $0.083^{* * *}$ \\
\hline & $(0.009)$ & $(0.010)$ & $(0.011)$ & $(0.013)$ & $(0.015)$ \\
\hline \multirow[t]{2}{*}{ Pre-trends } & -0.011 & -0.020 & -0.013 & -0.024 & -0.027 \\
\hline & $(0.017)$ & $(0.017)$ & $(0.021)$ & $(0.024)$ & $(0.027)$ \\
\hline \multicolumn{6}{|c|}{ Panel B: Effect of size on cumulative productivity growth $\left(\beta_{L B G}^{S}\right)$} \\
\hline \multirow[t]{2}{*}{ Permanent sample } & 0.009 & -0.010 & 0.011 & 0.001 & 0.036 \\
\hline & $(0.010)$ & $(0.011)$ & $(0.013)$ & $(0.014)$ & $(0.024)$ \\
\hline \multirow[t]{2}{*}{ Pre-trends } & -0.030 & $-0.049^{*}$ & -0.033 & -0.014 & 0.006 \\
\hline & $(0.020)$ & $(0.026)$ & $(0.020)$ & $(0.025)$ & $(0.031)$ \\
\hline
\end{tabular}

$s=1, \ldots, 5$ denotes the time periods after the shock that takes place as $s=0$. In the pre-trends exercise $s$ denotes periods before the shock. I denote significance at 10,5 and $1 \%$ with ${ }^{*},{ }^{* *}$ and ${ }^{* * *}$, respectively. Standard errors are denoted in parentheses

\subsubsection{Other robustness checks}

In the baseline results, inference is based on standard errors that ignore the estimation error in the propensity score. Abadíe and Imbens (2016) take into account the fact that the propensity scores are random variables and are estimated from the data (instead of being constants), and they derive the adjustment to the large sample variance of the estimated treatment effects. Table 7 reports the cumulative GBL and LBG effects and their corresponding standard errors estimated when considering the approach in Abadíe and Imbens (2016). In the case of GBL results in Panel A, the estimates are highly significant and similar to those in the baseline results not accounting for the randomness of the propensity scores [see row (b) of Table 3]. Regarding the LBG results in Panel B, standard errors are now smaller with respect to the coefficient estimates for the first 2 years after the size shock $(s=1$ and $s=2)$. However, the statistical significance of the effects completely vanishes after the third period $(s=3)$ as in row (d) of Table 3. I thus conclude that considering the asymptotic distribution in Abadíe and Imbens (2016) has no impact on the conclusions from the baseline results.

The baseline estimates control for selection on observables by including the following firm covariates: lagged high growth status, total factor productivity, size, export status, wages, and age. Financial variables are thus not included in the set of observable characteristics that might correlate with the high-growth indicators. However, access to finance may well be correlated with firms' growth performance in terms of both productivity and employment. If this is the case, a positive effect from highgrowth productivity to employment growth could be driven by differences in the access to finance. For instance, high-growth episodes may improve firms' ability to raise funding, and this improvement would generate employment growth rather than the productivity shock per se. In order to control for this possibility, we follow Fazzari 
Table 7 Estimated GBL and LBG effects-Robustness (IV)

\begin{tabular}{llllll}
\hline$s$ & 1 & 2 & 3 & 4 & 5 \\
\hline \multicolumn{2}{l}{ Panel A: Effect of productivity on cumulative size growth $\left(\beta_{G B L}^{S}\right)$} & & & \\
\multicolumn{7}{c}{ Abadíe and Imbens (2016) } & $0.019^{* * *}$ & $0.031^{* * *}$ & $0.039^{* * *}$ & $0.073^{* * *}$ & $0.082^{* * *}$ \\
& $(0.004)$ & $(0.005)$ & $(0.007)$ & $(0.009)$ & $(0.011)$ \\
Access to finance & $0.016^{* * *}$ & $0.033^{* * *}$ & $0.046^{* * *}$ & $0.055^{* * *}$ & $0.072^{* * *}$ \\
& $(0.004)$ & $(0.005)$ & $(0.006)$ & $(0.007)$ & $(0.009)$ \\
Panel B: Effect of size on cumulative productivity growth $\left(\beta_{L B G}^{S}\right)$ & & 0.005 & 0.002 \\
Abadíe and Imbens (2016) & $0.019^{* * *}$ & $0.024^{* * *}$ & 0.003 & $(0.012)$ & $(0.013)$ \\
Access to finance & $(0.005)$ & $(0.007)$ & $(0.009)$ & -0.005 & 0.004 \\
& $0.023^{* * *}$ & $0.018^{* * *}$ & 0.002 & $(0.032)$ & $(0.010)$ \\
\hline
\end{tabular}

$s=1, \ldots, 5$ denotes the time periods after the shock that takes place as $s=0$. "Abadíe and Imbens (2016)" refers to the use of the asymptotic standard errors derived in Abadíe and Imbens (2016), which take into account the estimation error in the propensity score. "Access to finance" refers to the inclusion of firms' cash-flow among the control variables in the matching to ensure that differences in firm's financial restrictions do not bias the baseline estimates. I denote significance at 10,5 and $1 \%$ with $*,{ }^{* *}$ and ${ }^{* *}$, respectively. Standard errors are denoted in parentheses

et al. (1988) and include firms' cash-flow among the set of firm covariates when performing the matching in the baseline specification. ${ }^{16}$ The estimated effects are reported in Table 7 under the label "Access to finance". The findings in the baseline specification remain robust to the inclusion of financial variables in the matching procedure. I can thus conclude that the estimated effect from productivity to employment growth is not driven by differences in access to finance between control and treated firms.

\section{Concluding remarks}

Large firms are more productive than small firms. The levers that firm managers can use to increase size and productivity are the same, namely, managerial talent, employee quality, and/or innovation. Therefore, establishing the direction of causality between size and productivity represents a challenge. This paper investigates this issue by exploiting a bi-directional identification strategy together with standard matching methods applied to a representative sample of Spanish firms. My results indicate that productivity growth may cause employment growth. In contrast, size growth defined by employment does not result in significant productivity gains.

\footnotetext{
16 Cash-flow is defined as the sum of net income, depreciation, and extraordinary income. Positive cashflow indicates that a firm's liquid assets are increasing, enabling it to settle debts, reinvest in its business, return money to shareholders, pay expenses and provide a buffer against future financial challenges.
} 
Open Access This article is distributed under the terms of the Creative Commons Attribution 4.0 International License (http://creativecommons.org/licenses/by/4.0/), which permits unrestricted use, distribution, and reproduction in any medium, provided you give appropriate credit to the original author(s) and the source, provide a link to the Creative Commons license, and indicate if changes were made.

\section{A Spanish firms in the EU context}

The Spanish firm size distribution is biased towards small firms in comparison to other developed countries. For instance, firms with less than 9 employees account for $41 \%$ of total employment in Spain while this figure is 20\% in Germany and 32\% in France. ${ }^{17}$ On the other hand, Spanish firms are also less productive than their European counterparts on average. For instance, average labour productivity of Spanish firms is $€ 39,140$ while this figure is $€ 51,610$ for Germany and $€ 53,820$ for France. ${ }^{18}$ The combination of these two results provides further evidence in favour of the sizeproductivity nexus based on cross-country variation of micro-level data.

In light of the positive association between size and productivity, it is typically argued that the large number of small firms in comparison with other developed economies is at the root of the low productivity growth in Spain (e.g. IMF 2015). However, the evidence in Fig. 4 casts doubt on this conclusion since Spanish firms are less productive than their European counterparts for all size classes.

Figure 4 shows four different measures of productivity by firm size in Spain relative to the other EU4 countries (Germany, France, and Italy). ${ }^{19}$ First, I compute firmspecific TFP for the four countries as described in Sect. 2.1 but using the Amadeus database. In particular, I follow the approach in Gal (2013) to ensure comparability of such productivity measures across countries. Second, I use the same TFP measure taken from the ECB's CompNet database that includes a usable sample of firms with more than 20 employees (see Lopez-Garcia et al. 2015). Third, I consider labour productivity, measured as value added per employee, from EUROSTAT's Structural Business Statistics (SBS). Fourth, I use labour productivity from an alternative source, the Entrepreneurship at a Glance (2014) report by the OECD. In all the four cases, Fig. 4 reports the ratio of average productivity in Spain to average productivity in the remaining EU4 countries. Moreover, I consider five size categories: (1) from 1 to 9 employees; (2) from 10 to 19 employees; (3) from 20 to 49 employees; (4) from 50 to 249 employees; (5) more than 250 employees. All the ratios refer to the total economy including manufacturing, trade, construction and services.

One lesson emerges from Fig. 4. Spanish firms are less productive than their European counterparts at all size categories and for all the four measures of productivity (i.e. the ratio is lower than 1 in all cases). For instance, labour productivity of Spanish firms with 1-9 employees (group 1) is 19\% lower than the corresponding EU4 average according to EUROSTAT and 36\% lower according to the OECD. In the case of large firms with more than 250 employees (group 5), Spanish firms' labour productivity is

\footnotetext{
17 See OECD Entrepreneurship at a Glance (2014) available at http://goo.gl/501vw3.

18 See EUROSTAT Structural Business Statistics (SBS) available at http://goo.gl/FDFj9G.

19 The lack of firm-level data precludes the consideration of a larger set of countries for the four measures analyzed here.
} 


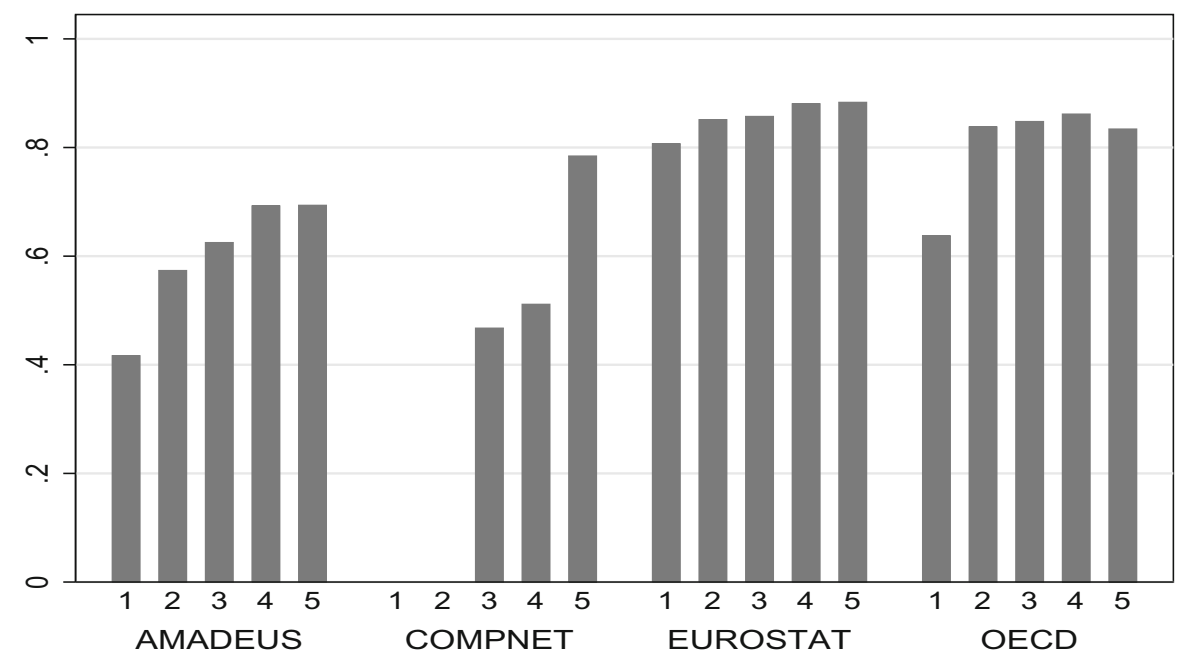

Fig. 4 Spain-to-EU4 productivity ratio by firm size. Notes Each bar plots the ratio of average productivity in Spain to average productivity in the remaining EU4 countries (Germany, France, and Italy). The five size categories reported are: (1) from 1 to 9 employees; (2) from 10 to 19 employees; (3) from 20 to 49 employees; (4) from 50 to 249 employees; (5) more than 250 employees. AMADEUS and COMPNET refer to total factor productivity ratios, while EUROSTAT and OECD refer to labour productivity ratios (see the main text for more details). AMADEUS and COMPNET figures refer to the period 2004-2012. EUROSTAT covers the period 2002-2013, and OECD refers to the year 2011. All the figures refer to the total economy including manufacturing, trade, construction and services

12 and $17 \%$ lower according to EUROSTAT and the OECD. Turning to total factor productivity, the productivity of Spanish firms in group 3 (20-49 employees) is 38 and 53\% lower than their EU4 counterparts according to AMADEUS and COMPNET, respectively. Large firms in group 5 (more than 250 employees) are 31 and 22\% less productive in Spain. Finally, it is worth mentioning that these figures remain qualitatively unchanged when looking at sector-specific ratios (see Fig. 5). To sum up, the productivity of Spanish firms is lower for all size categories. However, the productivity gap is smaller for large firms.

\section{B On the low productivity of Spanish firms}

Two empirical facts are discussed in the paper: (i) large firms are more productive than small firms (Sect. 3 in the main text); (ii) Spanish firms are less productive than their EU4 counterparts, even after accounting for sector and size (Appendix A). A possible interpretation of these facts is that Spanish firms are smaller because they are less productive.

This interpretation raises an obvious and crucial question. Why do Spanish firms are less productive than their European counterparts? Syverson (2011) provides an in-depth overview of the literature on the determinants of productivity at the firm level. Managerial talent, quality of inputs, and R\&D activities are identified as internal drivers of measured productivity differences across producers. Cross-country evidence 


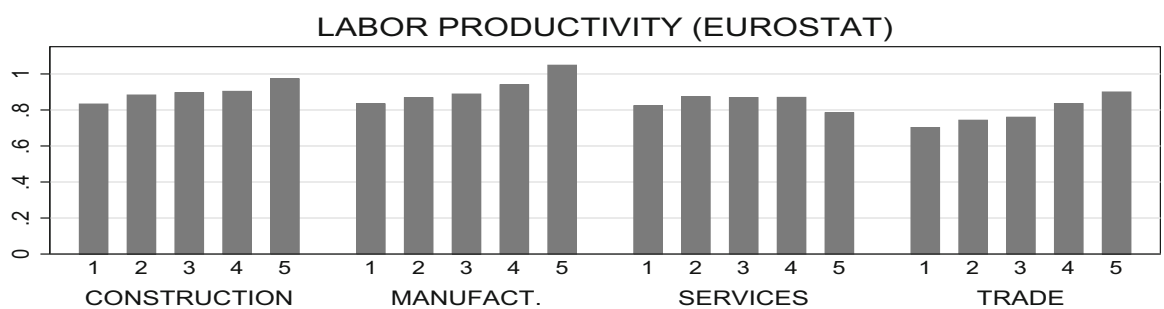

LABOR PRODUCTIVITY (OECD)

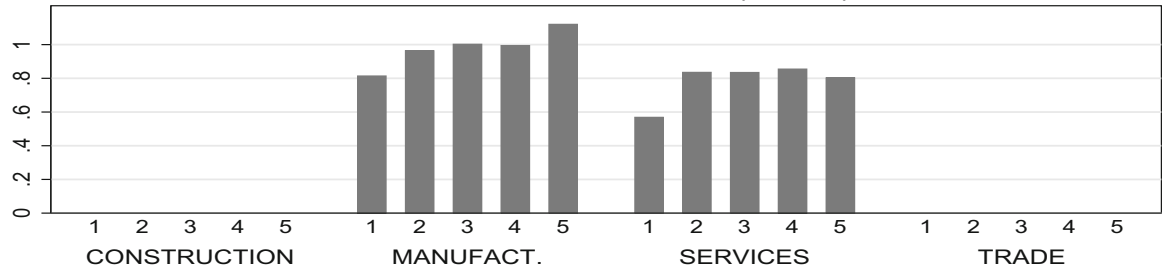

TOTAL FACTOR PRODUCTIVITY (AMADEUS)

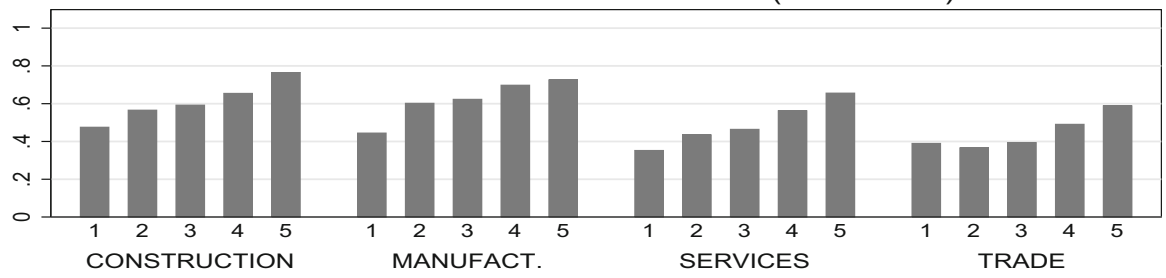

TOTAL FACTOR PRODUCTIVITY (COMPNET)

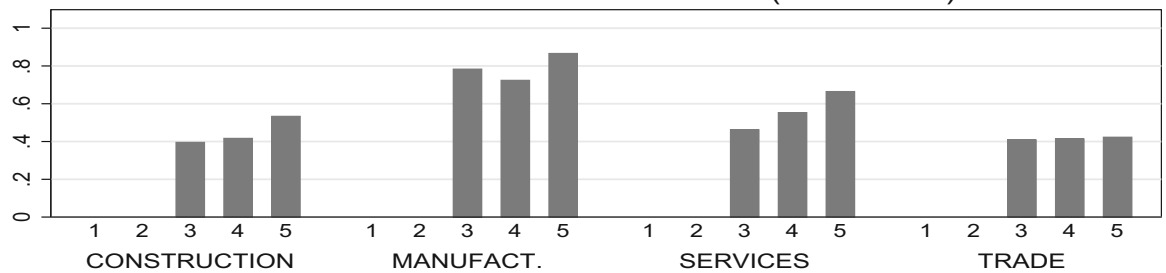

Fig. 5 Spain-to-EU4 productivity ratio by firm size and sector. Notes Each bar plots the ratio of average productivity in Spain to average productivity in the remaining EU4 countries (Germany, France, and Italy). The five size categories reported are: (1) from 1 to 9 employees; (2) from 10 to 19 employees; (3) from 20 to 49 employees; (4) from 50 to 249 employees; (5) more than 250 employees. Labor productivity figures cover the period 2002-2013 in the case of EUROSTAT and the year 2010 in the case of the OECD. Total factor productivity ratios from AMADEUS and COMPNET refer to the period 2004-2012

reveals that Spanish firms perform worse than their EU4 counterparts in all the three factors, which may explain, at least partially, their dismal performance in terms of productivity.

Managerial talent represents an obvious lever that can impact the productivity of a firm. Indeed, management can be interpreted as an unmeasured input in the production function. Managers coordinate the application of labor, capital, and intermediate inputs, which determines the ability of the firm to convert inputs into output. Data 
limitations have precluded the measuring of managerial talent across firms and countries until the World Management Survey (WMS) was released a decade ago. Bloom and Reenen (2007) and their team collected plant-level management practices data across multiple sectors and countries. The measured practices revolve around day-today and close-up operations on eighteen specific management practices in operations, monitoring, targets, and incentives. According to the latest release of the survey, in a scale from 1 to 5 the average score of Spanish firms was 2.75. This figure was 3.18, 3.00, and 2.95 in the cases of Germany, France, and Italy, respectively (see Bloom et al. 2014). To gauge the magnitude of these differences, which are economically important, note that the highest score, 3.29, corresponds to the US, while the lowest, 2.03, corresponds to Mozambique. I argue that poor managerial practices in Spanish firms may partially explain their low productivity. In fact, Bloom and Reenen (2007) show that the lower average management practice scores in some developing countries are driven by a large left tail of very poorly management practices, which goes in line with the larger gap in productivity of small Spanish firms with respect to EU4 firms. ${ }^{20}$

The productive effects of innovation, information technology, and research and development (R\&D) have been the subject of intense study. For instance, Doraszelski and Jaumandreu (2013) find that R\&D explains a substantial amount of productivity growth using a panel of Spanish firms, and they also develop a model in which firm productivity growth is the result of R\&D expenditures with uncertain outcomes. ${ }^{21}$ While $\mathrm{R} \& \mathrm{D}$ expenditures is only one of the many components of firms' innovative efforts, it is easy to measure. Indeed, cross-country statistics indicate that gross domestic expenditure on R\&D is substantially lower in Spain than in other European countries. Over the years 2003-2014, the average R\&D expenditure as a share of GDP was $1.22 \%$ in Spain, and 1.17, 2.14, and 2.63\% in Italy, France, and Germany, respectively. On the other hand, the share of innovative firms is $33.6 \%$ in Spain according to EUROSTAT. However, this figure is 56.1, 53.4, and 66.9\% in Italy, France, and Germany, respectively. ${ }^{22}$ It seems reasonable to think that the low innovative content of Spanish firms may also explain part of their productivity gap with respect to their European counterparts.

Standard input measures such as the number of employees or employee-hours do not capture differences in input quality. However, there exists a broad literature based on matched employer-employee datasets that documents the importance of labor quality as a driver of productivity. For instance, Ilmakunnas et al. (2004) show that workers' productivity is increasing in workers' education. Along these lines, there are reasons to think that Spanish workers are, on average, less productive than their EU4 counterparts. In particular, data from The Programme for the International Assessment of Adult Competencies - PIAAC — corroborates this concern. The PIAAC is a worldwide study of cognitive and workplace skills aiming to assess the skills of literacy, numeracy and

\footnotetext{
20 Note also that this hypothesis is consistent with the result in Medrano-Adan et al. (2017) that the lower organizational size diseconomies in the US may explain the larger average size and productivity of US firms relative to the Spanish ones.

21 Rochina-Barrachina et al. (2010) also find that the implementation of process innovations produces an extra productivity growth using a panel of Spanish firms.

22 The proportion of innovative firms in Spain is also lower by size categories.
} 
problem solving in technology-rich environments among the working-age population (for more details see OECD 2013). The average score is 249 in Spain, while it is 249, 258, and 271 in Italy, France, and Germany, respectively. These figures indicate that workplace skills of employees in Spanish firms are worse on average, which may well result in lower productivity at the firm level.

\section{Additional figures}

See Fig. 6.
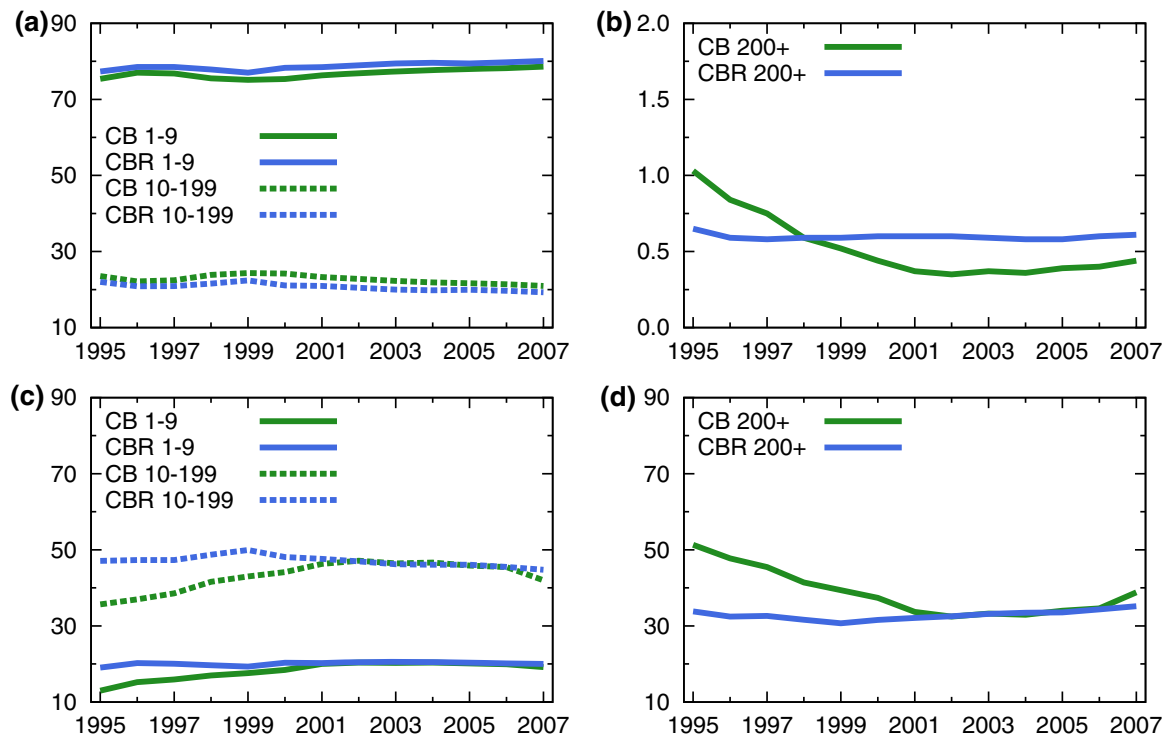

Fig. 6 Size distribution of firms, 1995-2007. Notes a plots the percentage number of firms with 1-9 workers and 10-199 workers both for our sample from the Central de Balances (CB) and for the census from the Central Business Register (CBR). b Does the same for firms with $200+$ employees. c, d Report the employment shares in the same size categories

\section{References}

Abadíe A, Imbens G (2016) Matching of the estimated propensity score. Econometrica 84:781-807

Basco S, Lopez-Rodriguez D, Moral-Benito E (2018) Housing bubbles and misallocation: evidence from Spain. Working paper

Becker S, Ichino A (2002) Estimation of average treatment effects based on propensity scores. STATA J 2:358-377

Bento P, Restuccia D (2017) Misallocation, establishment size, and productivity. Am Econ J Macroecon 9(3):267-303

Bloom N, Reenen JV (2007) Measuring and explaining management practices across firms and countries. Q J Econ 122:1351-1408 
Bloom N, Lemos R, Sadun R, Scur D, Reenen JV (2014) JEEA-FBBVA lecture 2013: the new empirical economics of management. J Eur Econ Assoc 12:835-876

Conesa J, Kehoe T (2017) Productivity, taxes, and hours worked in Spain: 1970-2015. SERIEs 8:201-223

Daunfeldt S, Elert N, Johansson D (2010) The economic contribution of high-growth firms: do definitions matter?. The Ratio Institute, Stockholm

Dehejia R, Wahba S (2002) Propensity score-matching methods for nonexperimental causal studies. Rev Econ Stat 84:151-161

De Loecker J (2007) Do exports generate higher productivity? evidence from Slovenia. J Int Econ 73:69-98

Díaz A, Franjo L (2016) Capital goods, measured TFP and growth: the case of Spain. Eur Econ Rev 83:19-39

Doraszelski U, Jaumandreu J (2013) R\&D and productivity: estimating endogenous productivity. Rev Econ Stud 80:1338-1383

Du J, Gong Y, Temouri Y (2013) High growth firms and productivity_evidence from the United Kingdom. Nesta working paper no. 13/04

Farinas J, Huergo E (2015) Demografía Empresarial en España: Tendencias y Regularidades, FEDEA No. 2015/24

Fazzari S, Hubbard G, Petersen B (1988) Financing constraints and corporate investment. Brook Pap Econ Act 1:141-195

Gal P (2013) Measuring total factor productivity at the firm level using OECD-ORBIS. OECD economics department working papers, no. 1049

García-Santana M, Pijoan-Mas J (2014) The reservation laws in india and the misallocation of production factors. J Monet Econ 66:193-209

Garcia-Santana M, Moral-Benito E, Pijoan-Mas J, Ramos R (2016) Growing like Spain: 1995-2007. CEPR working paper

Garicano L, LeLarge C, Van-Reenen J (2016) Firm size distortions and the productivity distribution: evidence from France. Am Econ Rev 106(11):3439-3479

Gourio F, Roys N (2014) Size dependent regulations, firm size distribution, and reallocation. Quant Econ 5:377-416

Guillamon C, Moral-Benito E, Puente S (2017) High growth firms in employment and productivity: dynamic interactions and the role of financial constraints? Banco de España working paper 1718

Guner N, Ventura G, Xu D (2008) Macroeconomic implications of size-dependent policies. Rev Econ Dyn 11(4):721-744

Halkos G, Tzeremes N (2001) Productivity efficiency and firm size: an empirical analysis of foreign owned companies. Int Bus Rev 16:713-731

Heckman J, Ichimura H, Todd P (1997) Matching as an econometric evaluation estimator. Rev Econ Stud 65:261-294

Henrekson M, Johansson D (2010) Gazelles as job creators: a survey and interpretation of the evidence. Small Bus Econ 35:227-244

Hsieh CT, Klenow PJ (2009) Misallocation and manufacturing TFP in China and India. Q J Econ 124(4):1403-1448

Ilmakunnas P, Maliranta M, Vainiomäki J (2004) The roles of employer and employee characteristics for plant productivity. J Prod Anal 21:249-276

IMF (2015) Obstacles to firm growth in Spain. IMF country report no. 15/233

Jovanovic B (1982) Selection and the evolution of industry. Econometrica 50:649-670

Levinsohn J, Petrin A (2003) Estimating production functions using inputs as controls for unobservables. Rev Econ Stud 70:317-342

Lopez-Garcia P, Puente S (2012) What makes a high-growth firm? a dynamic probit analysis using Spanish firm-level data. Small Bus Econ 39:1029-1041

Lopez-Garcia P, di Mauro F et al (2015) Assessing European competitiveness: the new CompNet microbased database. European Central Bank Working Papers, No. 1764

Mas M, Pérez F, Uriel E (2013) Inversión y stock de capital en Espa na (1964-2011). Evolución y perspectivas del patrón de acumulación, Fundación BBVA: Bilbao

Medrano-Adan L, Salas-Fumas V, Sanchez-Asin J (2017) Firm size and productivity from occupational choices. Mimeo

Melitz M (2003) The impact of trade on intra-industry reallocations and aggregate industry productivity. Econometrica 71:1695-1725

OECD (2013) OECD skills outlook 2013: first results from the survey of adult skills. OECD Publishing, Paris 
Olley S, Pakes A (1996) The dynamic of productivity in the telecommuunications equipment industry. Econometrica 64:1263-1297

Ramos R, Moral-Benito E (2017) Agglomeration by export destination: evidence from Spain. J Econ Geogr. https://doi.org/10.1093/jeg/lbx038

Rapping L (1965) Learning and World War II production functions. Rev Econ Stat 47:81-86

Rochina-Barrachina M, Manez J, Sanchis-Llopis J (2010) Process innovations and firm productivity growth. Small Bus Econ 34:147-166

Rosenbaum P, Rubin D (1983) The central role of the propensity score in observational studies for causal effects. Biometrica 70:41-55

Syverson C (2011) What determines productivity? J Econ Lit 49:326-365

Thompson P (2001) How much did the Liberty shipbuilders learn? new evidence for an old case study. J Polit Econ 109:103-137

Wooldridge J (2002) Econometric analysis of cross sections and panel data. The MIT Press, Cambridge

Wooldridge J (2009) On estimating firm-level production functions using proxy variables to control for unobservables. Econ Lett 104:112-114

Publisher's Note Springer Nature remains neutral with regard to jurisdictional claims in published maps and institutional affiliations. 